\title{
IMÁGENES DEL Holocausto. ANÁlisis DE LA ZONA GRIS Y SU REPRESENTACIÓN EN EL CINE CONTEMPORÁNEO
}

\section{Holocaust's Images. Analysis of "The Grey Zone» and its Repre- sentation in Contemporary Cinema}

\author{
Elios MENDIETA RODRÍGUEZ \\ Universidad Complutense de Madrid, España \\ E-mail: eliosmen@ucm.es \\ (iD) https://orcid.org/0000-0001-8753-9102
}

Fecha de recepción del artículo: 13/05/2020

Fecha de aceptación definitiva: 21/07/2020

\begin{abstract}
RESUMEN
En sus memorias como superviviente de Auschwitz, el escritor Primo Levi desarrolló el concepto de zona gris para explicar las diferentes maneras en que el régimen nazi hacía partícipe a su enemigo judío en el proceso de su propia destrucción, produciéndose una cierta connivencia entre víctima y verdugo. No obstante, este concepto se extendió rápidamente más allá de los márgenes del campo y se ha convertido en un marco de pensamiento necesario para entender, con mayor distancia temporal, lo que ocurrió durante la Shoah, materializándose la agrisada condición de diversas maneras en el presente. Setenta y cinco años después del final de la Segunda Guerra Mundial, el cine mantiene su gran fuerza para reactualizar el debate sobre el Holocausto por medio de las imágenes. Los distintos textos fílmicos recientes sobre esta temática atestiguan la importancia de recordar lo que sucedió para que el genocidio judío no caiga en el olvido, más aún cuando los supervivientes vivos son cada vez menos. En este sentido, el propósito del presente artículo es analizar cómo la zona gris desarrollada por Levi -y sus diversas lecturas contemporáneas- se manifiestan en el cine actual, para entender la importancia del concepto y su potencial contribución para una nueva ética y estética.
\end{abstract}

Palabras clave: Cine; Zona Gris; Claude Lanzmann; László Nemes; Primo Levi; Shoah.

\begin{abstract}
In his memoirs as an Auschwitz survivor, Primo Levi developed the concept of grey zone to explain the different ways in which the Nazi regime led its Jewish enemy to a process of self-destruction by diffusing the line between victim and executioner. In the aftermath of Auschwitz, this concept quickly spread beyond the limits of the camp and promptly became a necessary piece for the understanding of what happened during the Holocaust, above all due to the accuracy of a concept, grey zone, that still interact with the present. Seventy-five years after the Second World War finished, cinema is one key actor in the preservation of the debate on the Holocaust thanks to the strength of its images. Recent different films on this subject evidence the importance of remembering what happened then so that the memory of the Jewish genocide could be maintained, especially when
\end{abstract}




\begin{abstract}
the survivors are fewer. In this sense, the aim of this article is to study how that concept of grey area developed by Levi -and its different contemporary interpretations- is manifested in today's cinema, in order to understand the importance of the term and how it has been potentially nourishing a new ethics and aesthetics.
\end{abstract}

Key words: Cinema; Grey Zone; Claude Lanzmann; László Nemes; Primo Levi; Shoah.

\title{
1. Introducción
}

"Recordar la zona gris de Levi quizá puede ayudarnos a anticipar la emergencia de zonas grises en nuestro tiempo" (Mayorga, 2016: p. 40). Este concepto, desarrollado por Primo Levi (1919-1987) en sus testimonios sobre su experiencia como prisionero del Tercer Reich en Auschwitz -especialmente en Los bundidos en los salvados ( sommersi e $i$ salvati, 1986) - constituye una noción cuya actualidad ha conseguido extenderse más allá de las reflexiones sobre los campos de la muerte nazis y convertirse, como ha señalado Molinares Hassan (2012: p. 23), en elemento de una nueva ética. Desde que la noción fue planteada por el escritor turinés no han sido pocos los teóricos e investigadores que han debatido sobre la importancia de esta y, a su vez, han sido numerosos los que, con el paso de los años, han introducido el concepto, de manera directa e indirecta, en sus creaciones y lo han erigido como foco del debate, demostrando así la vigencia de esta zona gris en el pensamiento contemporáneo. El cine no ha sido una excepción, como se pretende demostrar en este estudio.

La zona gris es un territorio cuya estructura interna es extremadamente complicada, como reconoce Levi (2018: p. 498). Con este término designa a los presos de los campos que son cooptados por los mandos nazis para ejecutar las órdenes más violentas contra otros presos, creándose, de este modo, un espacio de connivencia o complicidad entre los verdugos y las víctimas, con lo que se genera una región extraordinariamente compleja en la que las víctimas se ven abocadas a colaborar en su destrucción, luchando unas contra otras. En su estudio sobre esta noción incluyó a los prisioneros-funcionarios, a los sonderkommando o las presidentes de los Consejos Judíos, entre otros (Levi, 2018: pp. 497-528). Este último caso ya evidencia que fuera de los campos también existen las zonas grises, lo que provoca que su análisis se pueda extrapolar a nuestras sociedades contemporáneas (Gaclerà, 2016: p. 177).

Aunque Auschwitz sea el epicentro de nuestro estudio al referirnos a la zona gris y su representación en las imágenes cinematográficas contemporáneas, el hecho de que el concepto sobrepase los límites del campo lo reviste de gran actualidad. Agamben señala que lo gris campa a sus anchas por la cotidianeidad y recalca lo importante de comprender su significado: "La zona gris no entiende de tiempo y está en todas partes; de ello proviene la angustia y la vergüenza de los supervivientes; y es también la vergüenza de quienes no hemos conocido los campos» (2009: p. 25).

En este contexto el cine emerge como espacio privilegiado para seguir pensando y reflexionando sobre una noción imprescindible ya que, como ha recordado el propio Levi, su conocimiento ayuda a conocer mejor la especie humana (2018: p. 501). La aparición de La zona gris (The Grey Zone, Tim Blake, 2001) supuso una aportación destacada, ya que esta película da a conocer a un público mayor -ya desde el propio título- los fundamentos del concepto al recrear en sus imágenes los intentos del sonderkommando por salvar la vida de una niña que había sobrevivido a las cámaras de gas. Se trata de una historia real que Blake recupera de las memorias del que fuera 
asistente en Auschwitz del doctor Mengele, el médico Miklós Nyiszli, y que también es central en El hijo de Saúl (Saul's fia, László Nemes, 2015), filme capital para estudiar la zona gris en el cine contemporáneo, como se demostrará.

El séptimo arte no ha dejado de reactualizar el debate sobre el Holocausto desde las primeras apariciones fílmicas sobre la gran tragedia hasta la actualidad, lo que resulta imprescindible, más aún por la consiguiente desaparición de los últimos supervivientes, lo que atestigua el papel relevante que han de jugar las imágenes cinematográficas para mantener en la población viva la memoria. Así, el objetivo de este artículo es analizar diversos textos fílmicos contemporáneos que se han adentrado en esta problemática y estudiar cómo plantean en sus imágenes el debate sobre la zona gris. Por una parte, nos acercamos al terreno del documental, por medio de Claude Lanzmann y su filme El último de los injustos (Le dernier de les injustes, 2013), en el que director francés recupera una entrevista a Benjamin Murmelstein, presidente del Consejo Judío de Terezín. Posteriormente, nos adentraremos en lo ficcional para comprobar diversas manifestaciones de lo gris en películas muy diferentes: la citada El hijo de Saúl y, de forma más breve, a otras dos propuestas cuyos directores no abordan el tema de la destrucción judía de forma directa, -como son Un lugar donde quedarse (This must be the place, Paolo Sorrentino, 2011) y Jojo Rabbit (Jojo Rabbit, Taiki Waititi, 2019)- pero que sí suponen acercamientos distintos al tema objeto de estudio en este artículo.

La elección de estas cuatro películas responde a la necesidad de una delimitación temporal para dotar al trabajo de una mayor contemporaneidad y, sobre todo, por los muy diferentes caminos en que lo gris se puede manifestar. Somos conscientes de que, al reducir el corpus de películas analizadas, quedan muchos textos fílmicos sin analizar que merecerían una mayor atención. Es el caso de películas que, de un modo u otro, ofrecen una lectura particular por la relación que en sus imágenes se ofrece sobre víctima y verdugo, como Los falsificadores (Die Falscher, 2007), de Stefan Ruzowitzky, o Amén (Amen, 2002), de Constantin Costa-Gavras; o las más comerciales La vida es bella (La vita è bella, 1997), de Roberto Benigni, o El niño con el pijama de rayas (The Boy in the Striped Pyjamas, 2008), por citar solo ejemplos conocidos. Si bien, consideramos que los cuatro filmes que se analizan en el presente artículo suponen una muestra representativa para abordar con garantías el objetivo del artículo. Pero antes del estudio en profundidad de cada una de las películas resulta necesario realizar una profundización teórica para comprender en mayor profundidad el concepto de zona gris.

\section{Planteamiento teórico: marco conceptual y metodológico}

"Las primeras amenazas, los primeros insultos, los primeros golpes no venían de los SS sino de los otros prisioneros, de 'compañeros', de aquellos misteriosos personajes que, sin embargo, se vestían con la misma túnica a rayas» (Levi, 2018: p. 483). La complejidad, ya aludida como característica de la zona gris, provoca que sea difícil determinar en numerosas ocasiones qué grupos de personas pertenecen o no a este resbaladizo terreno, como lo define Moreno Feliu (2010: p. 82). Son varios los teóricos que han intentado realizar una clasificación, no necesariamente cerrada, de aquellos grupos habitantes de esta zona, como Brown (2013), Moreno Feliu (2010) o Galcerà (2016). Conforme a las memorias de Levi, este último separa tres ámbitos. 
El primero lo conforman aquellos que poseen algún tipo de poder o privilegio en el campo y que derrumban la solidaridad esperada del prisionero recién llegado. El segundo grupo lo conforman los Sonderkommando o Escuadras Especiales que el italiano definió en Los hundidos y los salvados:

"Con esa denominación convenientemente vaga de Escuadra Especial nombraban las SS al grupo de prisioneros a quienes les era confiado el trabajo de los crematorios. A ellos les correspondía imponer el orden a los recién llegados (con frecuencia totalmente ignorantes del destino que les esperaba) que debían ir a las cámaras de gas; sacar de las cámaras los cadáveres; quitarles de las mandíbulas los dientes de oro; cortar el pelo a las mujeres; separar y clasificar las ropas, los zapatos, el contenido de las maletas; llevar los cuerpos a los crematorios y vigilar el funcionamiento de los hornos; sacar las cenizas y hacerlas desaparecer» (Levi, 2018, p. 510).

El tercero lo constituye la figura del líder judío de los guetos. Benjamin Murmelstein, en Terezín; Chaim Rumkowski, en Lodz; y Adam Czerniaków, en Varsovia, son los presidentes de Judënrat más conocidos.

Pero no solo conviene poner el foco en la víctima que colabora en el proceso de su propia destrucción. En el bando enemigo también aparecen figuras con tonalidad gris fuera del Lager, demostrando las múltiples raíces que tiene el concepto. Un ejemplo de ello lo constituye, para Levi, la sociedad alemana en su conjunto que vivió con comodidad durante los doce años que Hitler estuvo al frente de Alemania. En Si esto es un hombre (Si questo e un uomo, 1947) asegura que, si la inmensa mayoría de los alemanes no supo nada de lo que estaba pasando en los campos de exterminio, es porque no quería ni tenía intención de saber (2018: p. 221). Además, considera, por esta ceguera fingida y autoimpuesta, a gran parte de la sociedad alemana de la época como culpable. Sin embargo, no solo:

«Dentro de esta zona deben catalogarse, con distintos matices de calidad y peso, Quisling en Noruega, el gobierno de Vichy en Francia, el Judenrat de Varsovia, la República de Saló e, incluso, los mercenarios ucranianos y bálticos empleados por todas partes para hacer las tareas más sucias» (Levi, 2018: p. 503).

El hecho de que los diferentes países implicados en estos territorios grises hayan empezado a reconocer su parte de implicación en el desempeño de la conocida como «Solución Final» varias décadas después de que el conflicto acabase demuestra que el concepto de zona gris sigue tomando una importancia inusitada para entender el pasado y, además, confirma que es un concepto que se ha extendido y que no desapareció con el fin de los campos. Juan Mayorga -autor de dos piezas teatrales sobre el Holocausto en las que la zona gris toma una importancia destacada: Himmelweg (2003) y El cartógrafo (2009) - escribe que el concepto ha entrado en el debate de la política contemporánea, lo que hace necesario su conocimiento (2016: p. 40). Asimismo, Galcerà demuestra que lo gris, con el paso del tiempo y su desarrollo, se ha trasladado con facilidades de las zonas al ser humano (2016: p. 265).

En este sentido, el concepto posibilita un campo de pensamiento fecundo, pues lo gris se constituye en la contemporaneidad como el espacio en el que trascurre la experiencia humana y donde se puede estudiar la fusión y connivencia de la víctima y verdugo en muy diferentes niveles y en muy distintos contextos. Si bien, como advierte Galcerà en su estudio, esta enorme extensión también trae consigo un aspecto nega- 
tivo, y es que se pueden producir diversas derivas de la esencia original de la zona gris (2016: p. 30). Es este un peligro en el que también ha incurrido el séptimo arte.

De hecho, Levi advierte de la banalización que, en ciertas ocasiones, se da en el cine por la simplificación en que incurren los directores a la hora de representar el genocidio judío por la irrealidad del Lager que muestran. No es que el escritor italiano se muestre contrario a la ficción como método para intentar recordar la Shoah -como si hace, tal cual se estudiará, Lanzmann-, sino que exige un mínimo rigor y cierta fidelidad en el artificio artístico para que la película no coquetee con la trivialización de la barbarie. Un claro ejemplo de ello resulta la crítica que Levi efectúa de la ligereza y falseamiento con que la cineasta Liliana Cavani reflexiona sobre lo gris en su filme El portero de noche (Il portiere di notte, 1974), donde verdugo y víctima, como desarrolla, son presentados como cómplices por medio de una extraña relación sadomasoquista como si, en el fondo, ambos representasen la misma cara de una moneda en el campo. El escritor se muestra tajante:

"La directora de cine Liliana Cavani, a quien se le había pedido que resumiese el sentido de una bella y falsa película suya declaró: 'Todos somos víctimas o asesinos y aceptamos estos papeles voluntariamente. Solo Sade y Dostoievski lo han comprendido bien'. Dijo, también, que creía 'que en cualquier relación existe una dinámica víctima-verdugo expresada con mayor o menos claridad y generalmente vivida a nivel inconsciente'. Yo no entiendo de inconsciente ni de profundidades, pero creo que pocos entienden del tema, y que esos pocos son más cautos» (Levi, 2018: p. 508).

La lectura que el italiano denuncia el El portero de noche demuestra que en el quehacer artístico se pueden realizar interpretaciones erróneas de la zona gris que rebajan su importancia como marco de pensamiento para evocar el horror de la Shoah. Igualar el papel que víctima y verdugo tuvieron en los campos de exterminio, además de una banalización, supone una falsedad. En esta dirección, Mayorga advierte que "constatar que hay una zona en que las víctimas ayudan a los verdugos no es negar que hay víctimas y hay verdugos» (2016: p. 41). Esto es, la lectura original de la interpretación del escritor de lo gris separa claramente a los nazis de sus víctimas; unos son irrefutablemente culpables mientras que en el otro bando se han de atender las razones para intentar comprender el motivo de su ayuda al andamiaje criminal del Tercer Reich. Es por esta razón que, a la hora de juzgar a los pertenecientes a esta resbaladiza zona, Levi habla de impotentia judicandi (2018: p. 520), es decir, la imposibilidad de emitir un juicio sobre estas víctimas, pues entiende que todos y cada uno de ellos tienen una razón, aunque egoísta en gran parte de las ocasiones, para participar en la destrucción sistemática de sus iguales. Es este otro de los rasgos que atestiguan la enorme complejidad del concepto.

El cine ha suscitado infinidad de debates desde que aparecieron las primeras películas que mostraban o recreaban el horror de los campos. El propio Levi denunció el enorme trecho "entre las cosas tal y como eran 'allí' y las cosas tal y como las representa la imaginación corriente, alimentada por los libros, las películas y los libros correspondientes. Esta, fatalmente, se desliza hacia la simplificación y el estereotipo" (2018: p. 608). Al trazar una representación simplista del horror vivido o, más aún, al insinuar y mostrar que entre los presos y los gerifaltes nacionalsocialistas pudo existir una relación de igual a igual, no solo se transfigura la realidad de lo ocurrido en los campos, sino que conceptos imprescindibles para el pensamiento contemporáneo como el de zona gris pierden su relevancia. Y una consecuencia peligrosa de 
la realización de las representaciones y narraciones que simplifican e igualan el papel de verdugos y víctimas es la aparición de las derivas a las que hicimos referencia, pues se está produciendo una negación de lo que ocurrió en el pasado, lo que puede alimentar, como denunció el propio escritor, teorías revisionistas o negacionistas del Holocausto, como las surgidas con notable fuerza en los años setenta y ochenta del pasado siglo (Galcerà, 2016: p. 120).

Así, el séptimo arte juega un rol destacado como contenedor de la memoria y arma contra la asimilación simplista de la víctima al verdugo. Crear películas que reflexionen sobre esta tragedia no ha perdido un ápice de relevancia y, por ello, nos disponemos a analizar diferentes filmes, realizados en la última década, a partir de los cuales, de un modo u otro, se puede reflexionar sobre lo gris.

\section{Cine para repensar la zona gris: usos y abusos}

"¿Cómo describir el mayor de los infiernos?, ¿cómo narrar el horror del 'mayor crimen de todos los tiempos’?» (Levi, 2011: p. 50), ¿cuál es la manera correcta de representar Auschwitz — entendido este como una sinécdoque- y cómo superar la barrera de lo inefable?

Theodor Adorno fue uno de los pioneros en destacar la necesidad de hallar respuesta a la irracionalidad destructiva de los nazis en su ensayo Cultural Criticism and Society (1949), reimpreso posteriormente en Prisms, donde aseguró que escribir poesía después de Auschwitz era un acto de barbarie. La prescripción del filósofo ha sido mal interpretada y leída como una socorrida reducción aforística, cuando su dictamen pedía que el arte fuese consciente, en su concepción, del mal acaecido durante el genocidio judío. Así lo cree José Antonio Zamora (2008: pp. 283-284), quien interpreta en las palabras de Adorno el reto que concede a lo artístico para servir como portavoz histórico de la naturaleza oprimida, ya que el arte tiene una gran capacidad para hacer justicia a lo inefable con fórmulas que no transfiguren ni banalicen el sufrimiento y, a su vez, destaca el cine como medio más idóneo para ello.

En clave cinematográfica, si se piensa en los primeros filmes importantes aparecidos, se ha de poner en relevancia el trabajo de Alain Resnais en Noche y niebla (Nuit et Brouillard, 1955), por su logro de mostrar la crudeza de los campos. Sin embargo, no pocas fueron las críticas que recibió Gillo Pontecorvo al mostrar, mediante un travelling, un largo plano en el que se mostraba el cuerpo sin vida de una presa del campo -interpretada por Emmanuelle Riva- tras suicidarse arrojándose a las púas eléctricas, encuadrando el cadáver con un contrapicado del que sobresalía su mano, en Kapo (Kapò, 1959). Un movimiento de cámara innecesario para el cineasta Jacques Rivette, que lo calificó como «abyecto» (en Galcerà, 2016: p. 114). Pero es en los ochenta y los noventa cuando el debate sobre cómo se debía transmitir y representar el Holocausto se hizo más frecuente. Mucha culpa de la relevancia adquirida por el debate se debe a la aparición de Shoah (Shoah, 1985), de Lanzmann. El autor fue categórico en sus ideas: el Holocausto es un hecho impensable por lo que no se puede representar o, al menos, no se puede representar conforme se ha institucionalizado. De este modo, el francés instaura una personal moral de la representación del Holocausto en el cine, una especie de "Modo de Representación Holocaústico» (Rodríguez Serrano, 2013: p. 104), en el que profundizaremos más adelante. Esto le llevó a tener sonadas polémicas con determinados cineastas y a confrontar sus ideas con creadores y pensadores 
como Jean-Luc Godard, Georges Didi-Huberman, Steven Spielberg o Jorge Semprún. También Jacques Rancière se rebeló contra el alegato de lo inefable:

«El alegato de lo irrepresentable afirma que hay cosas que no pueden ser representadas sino en un cierto tipo de forma, por medio de un tipo de lenguaje propio de su excepcionalidad. Stricto sensu esta idea está vacía. Simplemente expresa una promesa, el deseo paradójico de que en el mismo régimen que suprime la conveniencia representativa de las formas respecto de los sujetos, aún existan formas propias que respeten la singularidad de la excepción» (2011: p. 143).

Su poderoso conjunto de filmes sobre el Holocausto hace imprescindible tener en cuenta la idiosincrasia creativa del francés a la hora de abordar un estudio sobre la zona gris. El último de los injustos es un texto imprescindible en este contexto, y por ello nos detendremos en su análisis, estudiando cómo dispone los testimonios y el material con el que cuenta para construir su relato documental.

En 2015 el estreno de El hijo de Saúl supuso un hito en el continuo debate, como mostraron los elogios de Lanzmann que, hasta la fecha, había criticado cualquier intento de hacer ficción de la realidad de los Lager. "No es una película sobre las cámaras de gas ni sobre la totalidad del exterminio: su ambición epistémica es modesta y eso le salva de la condena» (Arias Maldonado, 2019). Aunque El último de los injustos y el citado trabajo de Nemes constituyan dos acercamientos muy alejados -el primero, desde una esencia más documental que el segundo, que se vale de los mecanismos propios de la ficción aunque parta de ciertos hechos reales-, ambos son textos fílmicos imprescindibles para promover una lectura contemporánea de la zona gris en sus imágenes, pues -como recuerda Rancière- tanto el documental como la ficción constituyen tramas narrativas (2005: pp. 182-183).

\subsection{Lanzmann y el presidente del gueto de terezín}

En la fase inicial de preparación de Shoah, en 1975, Lanzmann entrevistó al rabino Benjamin Murmelstein, quien fue designado por los nazis como el tercer presidente del Consejo Judío de Terezín, en diciembre de 1944. Grabó diversas entrevistas con este a lo largo de una semana en su casa de Roma, pero todo el material se quedó fuera del resultado final del filme de 1985 -Lanzmann filmó más de 350 horas, de las cuales solo fueron utilizadas nueve y media en el metraje final-. Casi cuatro décadas después, el cineasta decide rescatar estas entrevistas, junto con imágenes filmadas en el presente, para conformar la película El último de los injustos, en la que Lanzmann visita el estado actual del gueto que Murmelstein presidió. El resultado de esta película demuestra que si existe un tema que la "constelación Shoah" viene a poner de relieve es la zona gris (Pena, 2014: 32). Como se refirió con anterioridad, para Levi los presidentes de los guetos constituyen uno de los más claros referentes de lo gris, dada la connivencia que hubo entre ellos y los nazis durante el conflicto bélico. En Shoah, Lanzmann -por medio de la entrevista que realiza al historiador Raul Hilbergrecuerda al que fuera presidente del gueto de Varsovia durante tres años, Adam Czerniaków, que se suicidó en 1942 tras conocer que no había podido evitar las primeras deportaciones desde el gueto que dirigía a Treblinka.

Posteriormente, en 2001, estrena Algo vivo pasa (Un vivant qui passe), donde el francés vuelve a reciclar horas de grabación que no introdujo en Shoah. En este 
caso entrevista a Maurice Rossel, representante del Comité Internacional de la Cruz Roja que visitó, en pleno auge de las deportaciones, el gueto de Terezín, y que en su informe redactó no haber detectado nada anómalo en su inspección. Rossel, protagonista de la obra de Mayorga Himmelweg, es uno de los más conspicuos representantes de lo gris fuera del campo. En la obra estrenada en 2013 esta zona sobrevuela gran parte de las secuencias, pues Lanzmann lleva al espectador a que se pregunte, dadas las respuestas del protagonista, si realmente Murmelstein, quien trabajó mano a mano con el nazismo y -más concretamente- con Adolf Eichmann, hizo todo lo que pudo para salvar al mayor número posible de judíos o si, por el contrario, no dudó en beneficiarse de su posición privilegiada para sentirse más a salvo.

El cineasta se muestra inquisitivo en determinadas preguntas e, incluso, reprocha a su entrevistado que en la descripción que realiza de Terezín no pinte el gueto como el infierno que realmente fue. Es el proceder escogido por Lanzmann para convertir el testimonio en material digno de documental. Pilar Carrera y Jenaro Talens escriben que, para convertir el registro obtenido en un relato documental "se necesita una estructura retórica que permita integrar las imágenes en un todo coherente y estructurado. La realidad es muda o bien habla demasiado, pero no sobre lo verdaderamente relevante. Hay que sacarle las palabras a la fuerza» (2018: p. 37). A la realidad testimonial obtenida por estas preguntas directas de Lanzmann, también se le hace hablar mediante la narración y la posterior edición, y es lo que hace el cineasta al ensamblar las declaraciones obtenidas en 1975 con las grabaciones del estado actual del gueto. Este ensamblaje de fragmentos es lo que Abraham Moles define como "creatividad" (en Carrera y Talens, 2018: p. 38). Si bien, ante los duros interrogantes del cineasta, el rabino se defiende: "No habría servido de nada tener arrebatos sentimentales [...] Estoy convencido de que si el gueto se conservó fue por el embellecimiento que hice de la ciudad" (Lanzmann, 2013).

Precisamente, el planteamiento de El último de los injustos que propone Lanzmann se ha de encajar -según la clasificación efectuada por Carrera y Talens- dentro de la categoría de "documental de creación», ya que se le presupone notables valores artísticos y no está concebido para atraer a una multitud a su visionado. Si bien, como señalan ambos autores, lo creativo no está reñido con lo informativo:

«Podría decirse que cuanta más información contenga un documental, más creativo es [...] No se trata de que el documental nos cuente aparentemente muchas cosas; se trata de que nos haga ver con ojos nuevos lo que aparentemente ya conocíamos. Se trata de que nos enseñe a desconocer, y así nos abra nuevos horizontes sobre el mundo y sobre los seres humanos. El documental que más información nos da es el que convierte en un país extranjero lo que creíamos nuestro hogar. Ese podría ser considerado también el más creativo. Un documental creativo es aquel en que lo familiar se vuelve extraño y, al mismo tiempo, se abren nuevas perspectivas sobre una realidad que se daba por cerrada” (Carrera y Talens, 2018: p. 74).

Es, sin duda, esto lo que consigue Lanzmann con El último de los injustos y con su anterior archipiélago de películas sobre la Shoah: arrojar nueva luz sobre un hecho que ha sido ya muy trabajado, convirtiendo su material fílmico en un relato documental.

Otro de los rasgos que acompañan a lo gris, la imposibilidad de emitir un juicio certero sobre la víctima que muestra connivencia con su verdugo también parece reflejarse en el planteamiento fílmico que propone Lanzmann con sus preguntas. Si 
bien, las imágenes desmienten la imparcialidad lograda en la entrevista. Es algo que el cineasta no esconde. En los rótulos que introduce el director a modo de opening, nos informa que Murmelstein evitó muchas deportaciones y que no huyó tras la guerra, lo que le valió la pena de 18 meses de cárcel antes de ser absuelto. Más aún, en el final del documental, el director no oculta la simpatía que siente por su interlocutor, al que abraza y con el que charla de forma distendida por las avenidas empedradas de Roma. En este último paseo filmado, como si Murmelstein siguiese la impotentia judicandi proclamada por Levi, el rabino le espeta al director: «Se puede condenar a un presidente de Consejo Judío, pero no se le puede juzgar, porque uno no se puede poner en su lugar» (Lanzmann, 2013).

Como recuerda Arias Maldonado (2019), Lanzmann no rehuyó nunca una polémica y rara vez se negó a expresar su opinión, pese a que en las preguntas a Murmelstein procure no mostrar un juicio de valor. Pero sí lo hizo en las entrevistas concedidas tras el filme. Para él, en los guetos no podía existir la figura del colaboracionista, y se refiere a El último de los injustos como un intento de rehabilitar a su protagonista:

«No hay que olvidar que, antes de que le enviaran a Terezín, cuando estaba en Praga antes de la guerra, consiguió hacer salir de Austria a 123.000 judíos. Fue un trabajo colosal, increíble, sabiendo que tenía que negociar caso a caso con Eichmann, un burócrata, pero también un demonio. Consiguió que Terezín continuara abierto hasta el final de la guerra [...] Los judíos de Terezín lo condenaron por colaboracionista, pero eso fue una gran tontería” (Losilla, 2014: p. 24).

El filme de Lanzmann reviste gran relevancia para la zona gris por ser su protagonista el único presidente de los Consejos Judíos que sobrevivió a la guerra. Parte de estos fue enviada a las cámaras de gas tras un tiempo en sus puestos, mientras que otros tantos decidieron quitarse la vida. «La alternativa a la colaboración, en la mayoría de las ocasiones, consistió en el suicidio, como es el caso de Adam Czerniaków» (Galcerà, 2016: p. 163). Una vía de salvación de lo gris que no comparte Lanzmann: "Un hombre como Murmelstein estaba obligado a hacer lo que los nazis le ordenaban, no tenía otra opción, excepto el suicidio. Pero nadie está obligado a suicidarse, aunque otros lo hicieran» (Losilla, 2014: p. 24).

Otro momento en que se evidencia con claridad lo gris es cuando el director recuerda que Murmelstein fue declarado un Prominenz de categoría A, es decir, un funcionario del otro bando que contaba con gran número de privilegios. Se trata de un perfil creado por el nazismo que simboliza "la creación de un nuevo tipo de hombre, que no es ni un superhombre ni solo un infra hombre, sino un infra hombre superior» (Galcerà, 2016: p. 106). Murmelstein, ante el recordatorio de Lanzmann de este privilegio, defiende que esta posición le permitió poder ayudar más a los judíos del gueto, y recuerda que si colaboró con el Tercer Reich desde el inicio fue pensando en beneficio de los suyos: "Pude haber emigrado a América sin pagar cuotas como rabino o como profesor universitario, pero no lo hice» (Lanzmann, 2013).

La obra completa de Lanzmann es especialmente compacta y se sustenta en la necesidad de preservar la memoria, por medio de los testimonios de quienes vivieron el Holocausto, de un acontecimiento que considera inabarcable y cuyo sentido, según ha reiterado, considera obsceno intentar comprender o explicar. De echo, asegura que su documental de 1985 no representa la masacre: "Lanzmann asserts that his film Shoah forgoes any attempt to represent the Holocaust and declares any attempt to understand the event obscene» (Rothberg, 2000: p. 5). En El último de los injustos se vuelven 
a encontrar las señas de identidad de su moral de la representación: rechazo de la ficción en sus imágenes, instauración de la frialdad como única posición moral posible ante lo contado, concordancia de la palabra del testigo con los paisajes que acogieron la tragedia e instauración del rostro del entrevistado como pantalla metafórica sobre la que el espectador ha de interpretar el drama del relato. "Sus imágenes están elegidas de manera meticulosa para que encajen con los testimonios, dando forma a un sistema de correspondencias entre lo que oímos y lo que vemos" (Arias Maldonado, 2019). Ejemplo paradigmático de ello es la secuencia en que el propio Lanzmann, filmándose en 2013, lee fragmentos del libro que, en 1961, escribió el propio Murmelstein: Terezin, il ghetto modello di Eichmann, y lo hace en la actual estación ferroviaria de Bohusovice, situada a solo tres kilómetros de donde se encontraba el citado campo de Terezín.

Si bien, y a diferencia de los cuatro anteriores documentales sobre el Holocausto, Lanzmann sí decide introducir imágenes de archivo sobre este gueto: fotografías en las que se ve a un joven Murmelstein en los años cuarenta y una película de propaganda incautada a los nazis sobre Terezín. Pero más allá de esta excepcionalidad, las imágenes actuales aparecidas a lo largo del documental y las declaraciones del rabino vuelven a encajar y demostrar la validez de su estrategia dramática para hacer presente el pasado, escenificándose así una suerte de recuerdo escenificado, constituyéndose el relato documental estructurado necesario al que hacían referencia Carrera y Talens.

El último de los injustos constata que, frente a la voluntad nazi de ocultar y hacer desaparecer cualquier imagen del bárbaro crimen, se yergue la obra monumental de Lanzmann. Surge el testimonio como verdadero elogio de la memoria y como una de las vías idóneas para que el espectador pueda reflexionar sobre lo gris y su persistencia en la actualidad.

\subsection{El Hijo de Saúl y las escuadras de la muerte}

No han sido pocos los creadores que han ignorado las proclamas lanzmannianas contra la ficción y han apostado por alejarse de lo documental para intentar explicar el Holocausto.

"La memoria es obra de ficción. La 'ficción' en general no es la historia bella o la mentira vil que se oponen a la realidad [...] La ficción es la construcción, por medios artísticos, de un 'sistema' de acciones representadas, de formas ensambladas, de signos que se responden» (Rancière, 2005: p. 182).

El artificio artístico emerge como vía igualmente necesaria para tratar de comprender lo que ocurrió. Son numerosos los creadores que han apostado por ello y numerosos los pensadores que han manifestado un claro alegato por su validez. Lo inefable no lo solo reluce con el testimonio del testigo, por muy importante que este sea. Así lo cree Jorge Semprún, superviviente del campo de concentración de Buchenwald: "Contar bien significa: de manera que se sea escuchado. No lo conseguiremos sin algo de artificio. ¡El artificio suficiente para que se vuelva arte!» (2017: p. 140).

Lo ficcional sobre el genocidio nazi también actúa como marco de pensamiento idóneo sobre la zona gris, ya que es capaz de reflotar el debate sobre algunas de las señas de identidad de este resbaladizo terreno. En este contexto resulta imprescindible el análisis de El hijo de Saúl, el filme de Nemes que protagoniza un sonderkommando. 
En Los hundidos y los salvados Levi define a los que participaron en estas escuadras de la muerte como un caso límite de colaboración en lo gris, ya que todos ellos sabían que, transcurrido un periodo de tiempo breve en sus puestos -generalmente de dos o tres meses- acabarían siendo asesinados en las cámaras de gas: "Haber concebido y organizado las Escuadras ha sido el delito más demoniaco del nacionalsocialismo» (Levi, 2018: p. 513).

Estos prisioneros vivían rigurosamente separados de los demás, eran escogidos por su fortaleza física y tenían numerosos privilegios, entre los que se encontraba la posibilidad de mantener una buena alimentación, el consumo de alcohol y tranquilizantes e, incluso, poseer libros (Moreno Feliu, 2010: pp. 154-155). Aunque Levi reconoce que los elegidos para desempeñar estas funciones estaban abocados al enloquecimiento, vierte sus críticas sobre ellos por la brutalidad de su trabajo, pero, como ocurre con los presidentes de los Consejos Judíos, declara sobre la imposibilidad de juzgar a estas escuadras: "Creo que nadie está autorizado a juzgarlos, ni quien ha vivido la experiencia del Lager ni, mucho menos, quien no la haya vivido" (Levi, 2018: p. 518). Es este punto donde se ha de poner en valor el trabajo de Nemes: su relato sobre el sonderkommando Saúl supone una inmersión en el infierno y una reflexión continua sobre lo gris de sus acciones en el campo sin caer en la banalización ni emitir un juicio sobre su toma de decisiones, como ahora se analizará.

Existen dos hechos destacados que sirven como base histórica al relato ficcional de Nemes: la sublevación del sonderkommando del 7 de octubre de 1944, en la que se voló parte del crematorio tercero y que se tradujo en una huida abortada por los nazis, y el sorprendente descubrimiento de varios miembros de la escuadra de que una niña había salido con vida del gaseado en las cámaras. Sobre este inexplicable hecho referido en las memorias del médico Nyiszli se refiere Levi: "En el suelo se encontraron con una joven que aún vivía. Era un acontecimiento excepcional, único; tal vez los cuerpos hayan formado una barrera a su alrededor, hayan capturado un saco de aire que conservó el oxígeno» (2018: p. 515). Acostumbrados a lidiar con la muerte, el cuerpo con vida, aunque moribundo, de la niña provoca que los sonderkommandos se sientan interpelados y que intenten salvarla. Esta es la base de La zona gris de Blake, y también sirve como inspiración a Nemes.

En El bijo de Saúl el protagonista homónimo, en la tarea de transporte de cadáveres de las cámaras a los crematorios, descubre el cuerpo de un joven con vida, aunque no puede hacer nada por salvarlo -un gerifalte nazi lo descubre y, con sus propias manos, acaba ahogándolo-. Saúl cree ver en este «resucitado» a su propio hijo y, tras esto, decide ofrecer al cadáver del niño un entierro justo. Una operación titánica dado el contexto espacial en el que se encuentra, por lo que fracasa. Si bien, la tarea que emprende Saúl es el gran hecho para pensar la zona gris en la original propuesta del cineasta húngaro ya que, como él ha dicho, «enterrar al hijo es un acto de humanidad, el de un hombre al que su voz interior le dice que tiene todavía una oportunidad de seguir siendo un humano» (Pena, 2016: p. 7). La posibilidad de sentirse humano en el paradigma espacial de la deshumanización más atroz sirve para alabar la valentía de sus acciones, pero no se ha de olvidar que, al emprender esta tarea, Saúl pone en riesgo su propia vida y la de sus compañeros de las escuadras y, al mismo tiempo, dificulta una misión mayor en la que está implicado: la citada rebelión del grupo y la explosión del crematorio. Nemes enfrenta al espectador ante esta disyuntiva y pone en evidencia, más que nunca, lo gris de unos personajes cuyo destino no era otro 
que la muerte. Lo que registra Nemes es el intento de Saúl de salir de la oscuridad (Didi-Huberman, 2016: p. 22).

Para alcanzar la pretendida ambigüedad el director se ayuda de un original uso del medio cinematográfico, con un novedoso planteamiento ético y estético. La cámara acompaña y no se separa -salvo en contadísimas ocasiones- del rostro y la nuca de Saúl, pero lo que el espectador observa y escucha no es lo mismo que él, sino que ve y oye el infierno que está alrededor del personaje, sin coincidir exactamente con su mirada, con una profundidad de campo ínfima. Este uso provoca que en el filme prevalezca la mostración sobre la narración, al contrario que en Shoah. Para profundizar en ello, se ha de realizar un apunte narratológico sobre el punto de vista, analizando la ocularización y auricularización de El bijo de Saúl, dada la original propuesta que ofrece el director húngaro. André Gaudreault y François Jost definen la ocularización como «la relación entre lo que la cámara muestra y lo que el personaje supuestamente ve»(2001: p. 141), y distingue entre la interna -cuando el plano está anclado en la mirada de una instancia interna a la diégesis- y la cero -cuando no conlleva tal mirada-. Al no coincidir la visión del espectador y Saúl, en la película se produce este último caso: "Tanto los encuadres abiertos como los cerrados mantienen siempre la profundidad de foco al mínimo: sólo hemos podido ver enfocado nítidamente el cuerpo o la cara de Saúl. En ningún caso la cámara asume la mirada de ningún personaje o de un ojo interno a la diégesis» (Ferrando García y Gómez Tarín, 2018: p. 311). Una singular ocularización -dada la escasa profundidad de campo y la constante filmación del personaje central- que se rompe en la escena final, cuando Saúl observa al joven campesino polaco con el que se topa en su huida: la mirada del espectador coincide, ahora sí, con la del protagonista, con lo que se produce la ocularización interna secundaria, donde la subjetividad de la imagen está construida por el más típico plano-contraplano (Gaudreault y Jost, 2001: p. 142).

Es la última visión que tienen, tanto espectador como personaje, antes de que el propio Saúl sea asesinado por los nazis. Y es una imagen nítida, que contrasta con la fotografía borrosa del resto del filme con la que se ancla la escasa profundidad de campo. Nemes no muestra la maquinaria nazi del Holocausto, solo los ruidos de fondo dan fe de lo que ocurre. Y es por este motivo que la auricularización -o punto de vista sonoro, como recalca Lauro Zavala (2015: p. 26)- es también relevante de estudiar en esta cinta, ya que difiere por momentos. Aunque como reconocen Ferrando García y Gómez Tarín a efectos de localización espacial se produce una auricularización interna, en general prima la omnisciente, ya que «el nivel de sonido y su utilización discursiva están pasadas por el tamiz del ente enunciador» (2018: p. 311)». Pese a que el espectador no tiene una idea concreta del lugar en que Saúl se mueve en cada momento, sí sabe que se está llevando a cabo el genocidio nazi en el interior de un campo de exterminio, ya que el filme, en su conjunto, constituye una vorágine sonora del horror, un espacio claustrofóbico, compuesto de diálogos irreconocibles en varios idiomas y "gritos que se mezclan entre las órdenes de los verdugos y los alaridos de las víctimas, alientos entrecortados y un caos de sonidos difícil de reconocer que podrían pasar por conformar la banda sonora del infierno" (Mendieta Rodríguez, 2018: p. 271). Además, en la película se repiten los momentos de silencio, lo que supone una operación arriesgada ante el caos que se vive en el Lager. Es, sin duda, una película gris, por su planteamiento ético y estético, por el interesante uso del punto de vista, y por el marco que compone para el estudio del concepto, pues reflexiona sobre la supervivencia en los campos y sobre la imposibilidad, tan reclamada por el escritor italiano, 
de juzgar a aquellos que, como ocurrió con los sonderkommandos, establecieron una relación de connivencia con el enemigo nazi.

Todo ello lo logra Nemes con un gran respeto a la historiografía sobre la barbarie, sin caer en la trivialización de la tragedia y, además, sin renunciar a los mecanismos propios de la ficción. Del visionado del filme se extrae, para Violeta Kovacsics, la necesaria pregunta de "cómo filmar después de Auschwitz" (2016: p. 14). Una cuestión que constata la necesidad de las imágenes para seguir pensando el genocidio judío, para luchar contra el olvido y reflexionar sobre lo gris.

\subsection{Ficciones en el límite de lo gris}

Hecha la referencia a la capacidad indiscutible que posee el cine para seguir repensando la Shoah y la zona gris en la actualidad -como también muestran Oleksandr Kobrynskyy y Gerd Bayer (2015) o Aaron Kerner (2011)-, también se ha advertido, con Levi, de la simplificación en la que han incurrido numerosos directores a la hora de mostrar la realidad de los campos de la muerte y sus consecuencias futuras, lo que puede provocar ciertas derivas peligrosas (Galcerá, 2016: p. 112). Por ello, no todo vale en el ejercicio fílmico si se quiere analizar con profundidad y actualidad lo gris. En este sentido, y de forma breve, estudiamos el caso de dos películas contemporáneas que, de forma indirecta, se acercan a esta problemática.

Un lugar donde quedarse (2011), de Paolo Sorrentino, tiene como protagonista a Cheyenne, un músico retirado de los escenarios, taciturno y melancólico, que vive en Dublín una vida apática y sin estímulos. No obstante, un día recibe la llamada de un familiar, desde Estados Unidos, que le informa que su padre, al que lleva décadas sin ver y con el que no habla, está a punto de morir. Cheyenne decide tomar un avión a Norteamérica y despedirse de su padre, y allí descubre que este había sobrevivido al Holocausto -lo que su director muestra mediante la imagen, al contemplar Cheyenne el número tatuado en el brazo de su progenitor- y que una misión le había obsesionado toda su vida, desde que fue liberado: vengarse de un jefe nazi que le había humillado en el campo de exterminio. Como si de una redención necesaria se tratara, el protagonista decide hacer suya la voluntad de su padre de intentar dar caza a este nazi, que se halla escondido en algún lugar de la América profunda. Aunque la intención inicial de Sorrentino era realizar una película más centrada en el Holocausto (Gili, 2011: p. 26), lo cierto es que su reflexión gana peso en la parte final del filme, donde emerge como tema la venganza de la víctima. "L'inesorabile bellezza della vendetta: un'intera vita dedicata a vendicare un'umiliazione» (Vigni, 2014: p. 182).

Sobre el tema de la venganza de la víctima sobre el verdugo se refiere Levi en Los bundidos y los salvados: "Pido justicia, pero no soy capaz personalmente de liarme a puñetazos ni de devolver los golpes» (2018: p. 590). Tomarse la justicia por su mano, en un territorio como el gris caracterizado por la impotentia judicandi, parece promover cierta banalización. Si bien, como analiza Rodríguez Serrano, la venganza no se sustenta, en este filme, en la brutalidad física de la víctima hacia el verdugo, sino en la imagen (2015: p. 280). Y es bajo esta premisa donde el trabajo de Sorrentino toma relevancia para pensar lo gris: una de las obsesiones nazis era eliminar cualquier huella de la Solución Final, cualquier imagen que les delatase. Al final del filme Cheyenne encuentra al anciano que humilló a su padre, que padece una total ceguera -alegoría de esa eliminación de la imagen del horror pretendida por Hitler y sus secuaces- y comienza su venganza. En primer lugar, toma una fotografía del rostro 
del nazi, cuyo flash emite un sonido seco. Sin duda, Sorrentino evoca aquí la crueldad de la Gestapo, al equiparar el disparo de la cámara fotográfica con el que producían las pistolas de los guardias nazis. De este modo, resulta como si, al visionar la fotografía extraída del metafórico disparo, se percibiera un fragmento del pretérito que se manifiesta en la actualidad, extraído del correr del tiempo y trasladado al presente. Transcurridos más de cincuenta años del fin del exterminio judío, ya no hay bala que pueda ajusticiar al criminal Aloise Lange, por lo que la fotografía, en esta secuencia, toma una gran potencia metafórica. «No hay bala que pueda matarle, de ahí la fuerza simbólica de la fotografía» (Rodríguez Serrano, 2015: p. 280).

Acto seguido, Sorrentino ofrece la segunda parte de la venganza al mostrar al anciano desnudo vagando en el paisaje exterior nevado. Con esta imagen, aunque de forma más arriesgada, pretende evocar la misma situación que vivió su padre en el campo de exterminio cuando fue preso del nazismo. La extrema delgadez del personaje, su imposibilidad de caminar anclado a la nieve y totalmente desnudo recuerdan la conocida escultura El hombre que camina (L'bomme qui marche, 1961) de Alberto Giacometti, emblema universal del ser humano y sus padecimientos tras la destrucción de la Segunda Guerra Mundial y la Shoah: "La idea de que Giacometti ve al hombre como un ser único enfrentado al mundo y solo ante él» (Maubert, 2019: p. 116). La imagen artística, por tanto, como vehículo privilegiado para evocar la memoria, escenificar el recuerdo y culminarse la venganza.

Una lectura más polémica ha generado Jojo Rabbit (2019), donde se cuenta la historia de un niño alemán de diez años que siente devoción por el nazismo, lo que le lleva a alistarse en las juventudes del NSDAP y a tomar un amigo imaginario: Hitler, al que solo él puede ver. El dilema llega para el protagonista al descubrir que su madre -miembro clandestino de la resistencia- esconde a Elsa, una niña judía, en su casa. Poco a poco, en las charlas que mantienen los dos niños se empieza a generar una simpatía mutua: él descubre que ella no es un monstruo y, a su vez, la niña desarrolla cierto amor fraternal hacia Jojo: "It's a feel-good movie, all right, but one that uses the fake danger of defanged black comedy to leave us feeling good"(Gleiberman, 2019: p. 140).

Tampoco ayuda el rol del imaginario Hitler en la comedia, ya que es retratado como un ser absurdo, banal, infantilizado y poco inteligente en su relación con Jojo. Gavriel Rosenfeld asegura -en su libro Hi Hitler! How the Nazi Past is Being Normalized in Contemporary Culture (2014)-, que las representaciones del Holocausto y del Tercer Reich que caen en la zafia caricatura no ayudan a preservar una memoria justa de lo que aconteció entre 1933 y 1945, sino que, al contrario, se espolea el sentimentalismo y el moralismo, introduciendo a Hitler como una suerte de personaje pop en el imaginario. Como también añade Bradshaw sobre el largometraje de Waititi, no se trata de una crítica a la comedia como vía posible para relatar el horror nazi, sino al modo en que se realiza: "There's nothing wrong with refusing to take Hitler seriously [...] Jojo Rabbit fails to attack or even really notice evil, and the moments when people are shown hanged in the streets serve only to point up the gluten-free ahistorical silliness of everything else. There are no insights to be had -and no laughs» (Bradshaw, 2019).

A la trivialización del mal mediante el personaje de Hitler se ha de sumar la final amistad entre la joven judía y el entusiasta nazi, lo que produce una sensación de equiparación entre víctima y verdugo, a la manera de lo denunciado por Levi de la película de Cavani, que se hace patente con el encariñamiento total final y, especial- 
mente, en la última escena: ya finalizada la guerra, Elsa sale de su escondite y, antes de huir, baila junto a Jojo mientras de fondo suena Heroes, de David Bowie. El enemigo nazi es perdonado mediante la imagen, como si el sufrimiento de la niña judía escondida durante tantos años quedase, al instante, olvidado. Como ha escrito Kemp, la película solo puede tolerarse eif you accept the premise that it is possible to find the material for a lighthearted, zany comedy in the Holocaust» (2020: p. 71). Una simplificación de la historia que no ayuda a evitar malintencionadas derivas revisionistas y analogías entre víctimas y verdugos ${ }^{1}$.

\section{Conclusiones}

A la luz de las películas analizadas queda patente que no todo vale en el audiovisual si lo que se pretende es crear productos que sigan reactualizando el debate sobre el Holocausto y que promuevan la reflexión sobre la noción desarrollada por Primo Levi, y que tanta actualidad aún reviste, como es el concepto de zona gris. La banalización o la trivialización puede generar ciertas derivas peligrosas, más aún dada la enorme excepcionalidad de una masacre sin precedentes en la historia como fue la destrucción europea de los judíos. El cine, por su enorme poder para hacer memoria, puede erigirse como una de las principales armas contra la asimilación de la víctima al verdugo. El creador ha de proceder con cautela y respeto histórico para no caer en la simplificación de la realidad que, ya en los setenta, denunciaba el superviviente italiano en algunos filmes de la época. Y en la actualidad, ante la cada vez menor presencia de testigos directos de la Shoah, los textos fílmicos aparecidos han de seguir suscitando el recuerdo en sus imágenes y sus reflexiones, lo que acompañará el testimonio imperecedero de las víctimas, ya que, aún hoy, "nuestro tiempo y espacio no pueden ser pensados sin Auschwitz» (Mèlich y Bárcena, 2008: p. 258).

En su análisis de La zona gris de Tim Blake, Rodríguez Serrano diferencia dos matices en el cine a la hora de abordar la representación de la barbarie: la torsión histórica, que defiende como necesaria en cualquier propuesta audiovisual, y la ruptura de lo histórico. Este segundo ejercicio «implica que, en el juego emocional del espectador, los materiales de origen conducen de manera irremisible a una interpretación aberrada, a la contra de la verdad histórica» (2018: p. 116). Es esta la falsedad que Levi denunció de El portero de noche (1974), al equiparar de modo tan simple a víctima y verdugo, y es algo que parecen desprender algunas secuencias de Jojo Rabbit, si bien, derivas como las citadas no invalidan lo ficcional como medio necesario para seguir reflexionando sobre la Shoah y su representación. Así se demuestra en obras como Un lugar donde quedarse, donde Sorrentino ofrece al espectador, de forma simbólica y original, la mirada que los nazis negaron al mundo, y, más aún, en El hijo de Saúl, en

1. Al igual que el filme de Waititi, diferentes textos fílmicos contemporáneos han sido objeto de crítica por realizar una simplificación de la historia o una banalización de la misma en su propuesta. A ellos podríamos haber dedicado mayor espacio en el presente artículo, pero hemos decidido reducir el corpus con el objetivo de no alargar el artículo más de lo necesario, pues consideramos las películas elegidas representativas, como se expuso en el apartado introductorio. Ejemplos de películas que han sido acusadas de trivializar el horror de la barbarie nazi y de los campos son La lista de Schindler (Schindler's List, 1993), de Steven Spielberg, o las anteriormente citadas La vida es bella (1997), de Roberto Benigni, o El niño con el pijama de rayas (2008), de Mark Herman, entre otras. 
la que Nemes repiensa lo gris desde una de sus figuras más conspicuas y polémicas, la del sonderkommando.

El gran trabajo tras y delante de la cámara de Lanzmann en El último de los injustos también constata la viabilidad del documental para reactivar la memoria de lo acontecido. El francés rescata su entrevista con el único presidente de gueto que sobrevivió a la Segunda Guerra Mundial y al Holocausto: Benjamin Murmelstein. Las respuestas ofrecidas por este ante las punzantes, en ocasiones, preguntas del director evidencian el resbaladizo terreno de lo gris en que se movió el rabino.

Tres cuartos de siglo después de la liberación de los campos de exterminio nazis, el peligro del olvido del genocidio judío, ante la muerte de los últimos supervivientes y los errores de la memoria, es un riesgo. La necesidad, en este contexto, de productos audiovisuales que repiensen el Holocausto y demuestren la actualidad del concepto desarrollado por el escritor italiano es más imperiosa que nunca. De ahí su valor.

\section{Bibliografía}

Agamben, G. (2009). Homo Sacer III. Lo que queda de Auschwitz: el archivo y el testigo. Valencia: Pre-Textos.

Arias Maldonado, M. (2019). Claude Lanzmann, revisitado tras su muerte. Revista de Libros, 27/03/2019, https://www.revistadelibros.com/discusion/claude-lanzmann-revisitado-tras-su-muerte

Bárcena, F. y Mélich, J.C. (2008). La lección de Auschwitz. En Mate, R. (ed.), La filosofía después del Holocausto (pp. 257-276).

Bradshaw, P. (2019). 'Jojo Rabbit' review - Taika Waititi's Hitler comedy is intensely unfunny. The Guardian, 19/12/2019, https://www.theguardian.com/film/2019/dec/20/jojo-rabbit-review-taika-waititi-hitler-comedy

Brown, A. (2013). Judging 'Privilegied' Jews: Holocaust Ethics, Representation, and the 'Grey Zone'. Nueva York, Estados Unidos: Berghann Books.

Carrera, P. y Talens, J. (2018). El relato documental. Madrid: Cátedra.

Didi-Huberman, G. (2016) Sortir du noir. París, Francia: Les Editions de Minuit.

Ferrando García, P. y Gómez Tarín, F. (2018). La inmersión subjetiva de un relato fenomenológico. A propósito de El hijo de Saúl (Saul fia, Laszlo Nemes, 2015). Fotocinema. Revista Científica de Cine y Fotografía, 17, pp. 297-320. https://revistas.uma.es/index.php/fotocinema/article/view/5113/4825 DOI: https://doi.org/10.24310/Fotocinema.2018.v0i17.5113

Galcerà, D. (2016). La pregunta por el hombre: Primo Levi y la zona gris. Barcelona: Anthropos.

Gaudreault, A. y Jost, F. (2001). El relato cinematográfico: Cine y narratología. Paidós: Barcelona.

Gili, J. (2011). Raconter la Shoah à travers un homme d'aujourd hui. Positif, septiembre de 2011, $607,25-28$.

Gleiberman, O. (2020). Fashionable Fascists. Jojo Rabbit: Film Review. Variety, 345 (10), septiembre de 2019, 139-149.

Kemp, E. (2020). Jojo Rabbit [Reseña]. Sight and Sound, 30 (1), enero de 2020, 70-71.

Kerner, A. (2011). Film and the Holocaust: New Perspectives on Dramas, Documentaries, and Experimental Films. Nueva York: Continuum.

Kobrynskyy, O. y Bayer G. (2015). Holocaust Cinema in the Twenty-First Century. Memory, Images and the Ethics of Representation. Nueva York: Wallflower Press.

Kovacsics, V. (2016). El arte como descendencia. Caimán. Cuadernos de Cine, 45 (96), 12-14.

Lanzmann, C. (1985). Shoah. Francia: Les Films Aleph / Ministère de la Culture de la Republique Française.

Lanzmann, C. (2013) Le dernier des injustes. Francia: Synecdoche / Le Pacte / Dor Film Wien. 
Levi, P. (2011). Vivir para contar. Madrid: Diario Público.

Levi, P. (2018). «Los hundidos y los salvados», en Trilogía de Auschwitz (pp. 471-652). Barcelona: Península.

Levi, P. (2018). «Si esto es un hombre», en Trilogía de Auschwitz (pp. 9-246). Barcelona: Península.

Losilla, C. (2014). No soy prisionero de mi pasado. [Entrevista a Claude Lanzmann]. Caimán. Cuadernos de Cine, 74 (23), 22-24.

Maubert, F. (2019). El hombre que camina. Barcelona: Acantilado.

Mayorga, J. (2016). Elipses. Madrid: La Uña Rota.

Mendieta Rodríguez, E. (2018). Sumergirse en el infierno. El hijo de Saúl y la crisis de la representación de la imagen. Área Abierta., vol.18, 2, pp. 261-275. https://revistas.ucm.es/ index.php/ARAB/article/view/58412 DOI: https://doi.org/10.5209/ARAB.58412

Moreno Feliu, P. (2010). En el corazón de la zona gris: una lectura etnográfica de los campos de Auschwitz. Madrid: Trotta.

Molinares Hassan, V. (2012). La zona gris: imposibilidad de juicios y una nueva ética. Barranquilla, Colombia: Universidad del Norte Ediciones.

Nemes, L. (2015). Saul fia. Hungría: Laokoon Filmgroup.

Pena, J. (2014). La constelación Shoah. Caimán. Cuadernos de Cine, 74 (23), 30-32.

Pena, J. (2016). Viaje al corazón de la muerte. [Entrevista a László Nemes]. Caimán. Cuadernos de Cine, 45 (96), 6-8.

Rancière, J. (2005). La fábula cinematográfica. Barcelona: Paidós.

Rancière, J. (2011). El viraje ético de la estética y la política. Revista Fractal. https://www. mxfractal.org/JacquesRanciere.html

Rodríguez Serrano, A. (2013). La muerte que habla. La escritura del holocausto en La zona gris. Trama y fondo, 35, 103-116. http://www.tramayfondo.com/revista/libros/157/AaronRodriguezSerrano.pdf

Rodríguez Serrano, A. (2015). Espejos de Auschwitz. Santander: Shangrila.

Rosenfeld, G. (2014). Hi Hitler! How the Nazi Past is Being Normalized in Contemporary Culture. Cambridge: Cambridge University Press.

Rothberg, M. (2000). Traumatic Realism: The Demands of Holocaust Representation. Minnesota: Minnesota University Press.

Semprún, J. (2017). La escritura o la vida. Barcelona: Tusquets.

Sorrentino, P. (2011). This must be the place. Italia: Indigo Film / Lucky Red / Medusa Film.

Vigni, F. (2014). La maschera, il potere, la solitudine. Florencia, Italia: Azka.

Waititi, T. (2019). Jojo Rabbit. Estados Unidos: Defender Films / Piki Films / Czech Anglo Productions / TSG Entertainment.

Zamora, J.A. (2008). Estética del horror. Negatividad y representación después de Auschwitz. En Mate, R. (ed.), La filosofía después del Holocausto (pp. 277-300).

Zavala, L. (2014). Narratología y lenguaje audiovisual. [Libro en línea] https://www.researchgate. net/profile/Lauro_Zavala/publication/261760662_NARRATOLOGIA_Y_LENGUAJE_AUDIOVISUAL/links/0f317535724bc3b1da000000/NARRATOLOGIA-Y-LENGUAJE-AUDIOVISUAL. pdf 
